\title{
Knowledge, attitude and practice regarding clinical and self breast examination among radiology professionals
}

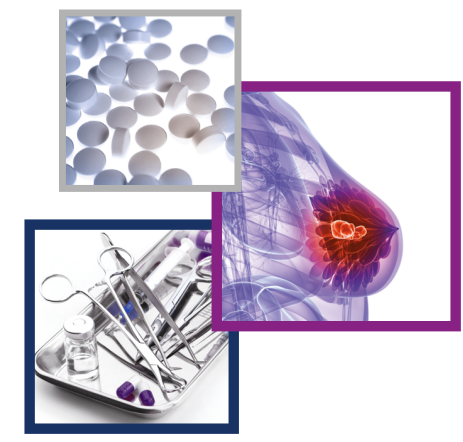

\author{
Mohammad Rawashdeh*,1, Maha Zaitoun ${ }^{1}$, Mark F McEntee², Mostafa \\ Abdelrahman1, Maha Gharaibeh ${ }^{3}$, Suha Ghoul ${ }^{4} \&$ Charbel Saade $^{5}$ \\ ${ }^{1}$ Faculty of Applied Medical Sciences, Jordan University of Science \& Technology, Irbid 22110, Jordan \\ ${ }^{2}$ Medical Image Optimisation \& Perception Group (MIOPeG), \& the Brain \& Mind Centre, Faculty of Health Sciences, The University \\ of Sydney, Sydney, New South Wales, Australia \\ ${ }^{3}$ Faculty of Medicine, Jordan University of Science \& Technology, Irbid 22110, Jordan \\ ${ }^{4}$ Diagnostic Radiology department, King Hussein Cancer Center, Amman 11941, Jordan \\ ${ }^{5}$ Department of Diagnostic Radiology, American University of Beirut Medical Center, Beirut, Lebanon \\ *Author for correspondence: marawashdeh@just.edu.jo
}

\begin{abstract}
Aim: This study aims to assess the knowledge, attitudes and practices of radiology professionals in Jordan in regard to breast cancer (BC) screening. Methods: An IRB approved, online-based study was carried out in Jordan. The participants were radiologists $(n=8)$ and radiographers $(n=64)$. Results: The results showed that although $61.8 \%$ of participants were knowledgeable about BC prevention, only $65.7 \%(n=48)$ of respondents performed breast self-examinations (BSE) on themselves, $28.7 \%(n=21)$ underwent clinical breast examination (CBE) and $15.1 \%(n=5)$ underwent either diagnostic or screening mammography. Conclusion: Radiology professionals are generally aware of the benefits of BC screening and its ability to facilitate early diagnosis of BC. Although some practitioners advise their relatives to perform BSEs and attend $C B E$, low percentages of respondents performed BSEs themselves or undergo CBE.
\end{abstract}

First draft submitted: 17 October 2018; Accepted for publication: 28 November 2018; Published online: 13 February 2019

Keywords: breast screening $\bullet$ breast self-examinations $\bullet$ clinical breast examination

Breast cancer (BC) is the most common cancer in women worldwide [1] as well as the second leading cause of cancer deaths in Jordan [2]. Since the 1970s, the 5-year survival rate in Jordan has risen from 50 to $80 \%$, mainly due to the improvement in diagnostic techniques and technologies that are associated with $\mathrm{BC}[3,4]$. However, higher death rates exist among low socio-economic sectors and certain ethnic groups [5]. Early detection is challenging as $\mathrm{BC}$ can be asymptomatic [6]. Detection of $\mathrm{BC}$ in its early stages can be achieved by different methods, including routine breast self-examination (BSE) and clinical breast examination (CBE) and mammography.

Screening mammography has been found to significantly reduce BC mortality rates in women aged between 50 and 74 years [7]. In addition, mammography is a valuable diagnostic tool; mammography can detect many smaller cancers, thus increasing the net benefit to the population as a whole [8]. Although mammography uses radiation, it uses much lower dose than ionizing modalities such as computed tomography or nuclear medicine (scintimammography), both rarely used for BC imaging, but higher than nonionizing examinations such as ultrasound or magnetic resonance imaging [9]. Mammography can either be performed when symptoms are present, called diagnostic mammography, or on healthy asymptomatic patients, called screening mammography. Early detection provides more effective treatment options with an overall better prognosis [10,11]. Screening is estimated to have saved $\$ 1.5$ bn in treatment costs in the USA [12].

BSE is a personal physical test, where women are encouraged to palpate their own breasts each month on the second week of their menstrual cycle to feel for any changes. BSE helps to alert women to any abnormalities in the breasts [13]. Regular BSE makes women more aware of their breasts, leading to a higher chance of detecting any changes in the breast tissue, thus leading to an earlier diagnosis of BC [14].

Future Medicine 
$\mathrm{CBE}$ is designed to find $\mathrm{BC}$ at an early stage before metastasizing, thus increasing the survival chances. $\mathrm{CBE}$ performed by a trained healthcare provider involves a physical examination of the breasts and underarm. $\mathrm{CBE}$ is a low-cost test that could improve the detection of $\mathrm{BC}$. CBE can form part of routine, periodic examinations, especially for women $<50$ and more than 69 years of age, for moderate- and high-risk women and for women who have had a BC [15].

The 'Jordan Breast Cancer Program' has published a set of guidelines for women in Jordan to follow. These guidelines include monthly BSE for all women postpuberty. Breast Screening in Jordan is a biennial mammography for women from 40 to 49 years and annually for women above the age of 50 years [16]. The Jordan Breast Cancer Program provides CBE free to women above the age of 40 years. The mammogram is provided at a subsidized cost of $\$ 42$ USD. A $20 \%$ discount is applied on multiple investigations, which include mammograms for the members of cancer care program [17]. The combination of these discounts and free services aims to reduce the barriers for women from all socio-economic backgrounds.

Although there are two studies examining knowledge, attitudes and practice among radiologists and whether or not they undergo breast-screening themselves [18,19], these studies have been limited to radiologists and did not include radiographers [19]. To the best of our knowledge, this is the first study to assess the level of knowledge, attitude and practice among radiology professionals (radiologists who interpret the imaging scans and radiographers who perform the scans) in performing BSE, CBE and mammograms on themselves and their relatives in Jordan. Additionally, this work aims to determine the barriers and enablers of BSE, CBE and mammography for radiologists and radiographers.

\section{Materials \& methods}

This cross-sectional study based on quantitative methodology was conducted over approximately in April of 2018. The study was an online-based survey (Google survey) carried out in Jordan. Eligible participants of the study were radiologists and radiographers, and these were recruited using two nonprobability sampling techniques; convenience and snowball sampling. A total of 72 respondents were recruited. Power analysis using Cohen's formula (1992) indicated that a sample of 72 would give a $90 \%$ chance of detecting correlations in \pm 0.223 at $<0.05$ level.

\section{Instruments \& materials}

Data were collected via a questionnaire consisting of 26 questions. The questionnaire was distributed among eight radiologists and 64 radiographers via a combination of social media and print. A printed version of the questionnaire was given out in King Abdullah Universal Hospital, Al-Ramtha and Royal Medical Services, Amman; the study sample was selected using the nonprobability convenience sample. The 26 questions were of multiple-choice type and short answer questions, divided into five parts.

In the first part, participants had to provide their age, hometown, gender, specialty in radiology, workplace and job type. The second part inquired about their experience in radiology department and in mammography in particular. The third part was designed to test participants' general knowledge on how common BC is in Jordan, and its symptoms. The fourth part was designed to explore attitudes in advising patients undergoing BSE, CBE and mammography and the accurate time for performing each investigation. The final part enquired of participants whether they had ever undergone any BSE, CBE or mammography themselves or recommended them to their relatives. Multiple-choice questions were used in section 1 and short answer questions were implemented for sections 2, 3, 4 and 5 .

\section{Statistical analysis}

Responses were transferred to an electronic spreadsheet for analysis; each was numerically coded to be entered SPSS (IBM Corp., released 2013. IBM SPSS Statistics for Windows, Version 22.0. Armonk, NY, USA: IBM Corp.) For statistical analysis, data were analyzed using the $\chi^{2}$ test, a one-way ANOVA, and the independent samples $t$-test; $\mathrm{p}$-values $\leq 0.05$ were considered significant.

\section{Results}

Characteristics of the participants are shown in Tables 1 and 2. The age of the respondents ranged from 22 to 59 years with a mean of 28 years. Most were female radiographers working fulltime in a public hospital and all were from Jordan. In total there were 56 females and 16 males, most of them working in public hospitals $(\mathrm{n}=37)$, university hospitals $(\mathrm{n}=22)$ and some in the private sector $(\mathrm{n}=13)$. 


\begin{tabular}{|c|c|c|c|}
\hline \multicolumn{2}{|c|}{ Characteristics } & \multirow{2}{*}{$\begin{array}{l}\text { Frequency }(n) \\
40\end{array}$} & \multirow{2}{*}{$\begin{array}{l}\text { Percentage (\%) } \\
(55.6 \%)\end{array}$} \\
\hline Age & $<25$ & & \\
\hline & $36-40$ & 6 & $(8.3 \%)$ \\
\hline & More than 40 & 6 & $(8.3 \%)$ \\
\hline Sex & Males & 16 & $(22.2 \%)$ \\
\hline \multirow[t]{2}{*}{ Job } & Radiologist & 8 & $(11.1 \%)$ \\
\hline & Radiographer & 64 & $(88.9 \%)$ \\
\hline \multirow[t]{3}{*}{ Speciality } & Breast imaging & 5 & $(6.9 \%)$ \\
\hline & Cardiovascular radiology & 6 & $(8.3 \%)$ \\
\hline & Musculoskeletal & 12 & $(16.7 \%)$ \\
\hline \multirow[t]{4}{*}{ Job type } & Full time & 45 & $(62.5 \%)$ \\
\hline & Part time & 27 & $(37.5 \%)$ \\
\hline & $6-10 \mathrm{~h}$ & 4 & $(5.6 \%)$ \\
\hline & $11-15 \mathrm{~h}$ & 1 & $(1.4 \%)$ \\
\hline
\end{tabular}

Table 2. Experience in mammography, in particular, the number of mammograms done or read yearly.

\begin{tabular}{|llll|}
\hline Questions & Answers & Frequency $(\mathbf{n})$ & Percentage (\%) \\
\hline Do you read/do mammograms & No & 32 & $(44.4 \%)$ \\
& Yes & 40 & $(55.6 \%)$ \\
\hline How many mammograms do you read & $0-240$ & 66 & $(91.7 \%)$ \\
per year & $241-480$ & 2 & $(2.8 \%)$ \\
& $481-960$ & 1 & $(1.4 \%)$ \\
\hline For how many years have you been & $961-1200$ & 3 & $(4.2 \%)$ \\
reading or performing mammograms & $6-5$ & 67 & $(93.1 \%)$ \\
& $11-15$ & 4 & $(5.6 \%)$ \\
\hline
\end{tabular}

The group of respondents had a high knowledge of breast examinations. As expected, $95.8 \%(n=69)$ of respondents believed that BSE was important for early diagnosis, with only three respondents believing the opposite. A total of $87.5 \%$ of respondents believed correctly that $\mathrm{BC}$ was one of the most common causes of death in Jordan. $51.4 \%(\mathrm{n}=37)$ correctly stated that cancers could be treated in its early stages with only surgery and $48.6 \%$ believed that BC could not be treated in its early stages with surgery alone. Surprisingly, numerous respondents did not choose the exact symptoms that could raise BC concerns properly, with only $12.5 \%(\mathrm{n}=9)$ knowing all of the correct symptoms (Table 3).

BSE, CBE and mammography together were recommended to relatives by $15.1 \%(\mathrm{n}=11)$ of participants and 84.9\% did not recommend BSE, CBE and mammography. Advising patients to perform BSE once a month was recommended by $69.4 \%(\mathrm{n}=50)$ while 'once every 2 months' was recommended by $20.8 \%(\mathrm{n}=15)$ and $9.7 \%$ $(\mathrm{n}=7)$ advised twice a month. Only $30.6 \%(\mathrm{n}=22)$ would correctly direct patients to do breast examination on day 5-7 of the menstrual period [20]; 45.8\% ( $\mathrm{n}=33$ ) of respondents indicated that they would direct their patients to do examination immediately after menstruations and 19.4\% $(\mathrm{n}=14)$ indicated they would not recommend it any particular time during the cycle. The independent sample t-test indicated that females would advise patients to undergo self-breast examination and mammography more often than males $(\mu=1.50, S D=0.713 ; \mathrm{p}=0.026$ $<0.05)$.

Table 4 summarizes the frequency of responses regarding whether the participants performed breast screening or not. The majority of respondents, including men, 65.7\% ( $n=48)$, do not perform BSE, while $34.2 \%(n=25)$ 


\begin{tabular}{|c|c|c|}
\hline Breast self-examination is important for early diagnosis & $69(95.8 \%)$ & $3(4.2 \%)$ \\
\hline $\begin{array}{l}\text { Breast cancer is among the three most common causes of death impacting } \\
\text { females in Jordan }\end{array}$ & $63(87.5 \%)$ & $9(12.5 \%)$ \\
\hline Can patients with early stage breast cancer be treated with only surgery & $37(51.4 \%)$ & $35(48.6 \%)$ \\
\hline Nipple inversion & $42(58.3 \%)$ & \\
\hline Ulceration & $20(27.8 \%)$ & \\
\hline Focal nodularity & $28(38.9 \%)$ & \\
\hline Asymmetry with other breast & $30(41.7 \%)$ & \\
\hline
\end{tabular}

said they do on themselves. Of those who do not, $29.2 \%(\mathrm{n}=21)$ said that they do not have time; $26.4 \%(\mathrm{n}=19)$ indicated that they lacked the technique of doing it; and $2.8 \%(\mathrm{n}=2)$ stated that they assumed that it was not a beneficial procedure. With CBE, 28.7\% $(\mathrm{n}=21)$ underwent this examination and the other $71.2 \%(\mathrm{n}=52)$ never did for several reasons including 25.0\% ( $\mathrm{n}=18)$ not having enough training, $15.3 \%(\mathrm{n}=11)$ not having enough time, $12.5 \%(\mathrm{n}=9)$ being afraid of actually finding a cancer and $4.2 \%(\mathrm{n}=3)$ 'seeing no benefit'. Two respondents thought that at under the age of 40 no CBE is needed.

With mammographic examination, $15.1 \%(\mathrm{n}=5)$ underwent a mammogram. Mammography every 2 years was recommended by $38.9 \%(\mathrm{n}=28), 48.6 \%(\mathrm{n}=35)$ suggested a yearly program of mammography and $12.5 \%$ $(\mathrm{n}=9)$ advised twice a year after the age of 40 .

None of the variables had significant effect on performing breast examination.

\section{Discussion}

Breast screening is one of the most efficient ways to detect lumps or masses before they start to metastasize [15]. BSE is simple, noninvasive and does not require much time [21]. Many studies worldwide have discussed the role of healthcare providers [21], students [20] and teachers [22] in routine emphasis of breast examinations (self, clinical and mammograms).

Previous work highlights the need for promotion of $\mathrm{BC}$ screening and more research about the topic in the Arab world. Although recent years show a slight increase in research in this area, further research is still needed if $\mathrm{BC}$ screening is to achieve earlier detection and the consequent increased treatment options. More research is needed to identify and mitigate the barriers associated with different populations in Arab countries before culturally appropriate, socially acceptable, effective intervention strategies can be recommended [14]. Healthcare professionals, including radiologists and radiographers, carry the responsibility of improving the society's health by being a direct source of accurate knowledge of breast examinations. In addition to that, they are also responsible for increasing awareness of $\mathrm{BC}$ to the public [23]. This awareness includes giving the public the ability to recognize and differentiate any changes in breast shape, size or skin texture. Furthermore, healthcare professionals are encouraged to improve the patient's awareness and attendance at breast screening. One way to do so is to model that behavior themselves. These healthcare professionals also carry the responsibility of changing public behaviors to reduce risk of cancer such as avoiding exposure to tobacco products, maintaining a healthy weight, staying physically active throughout life, and consuming a healthy diet, as these activities can substantially reduce one's lifetime risk of developing, or dying from, cancer [18]. Since radiology professionals might have a considerable influence on their patients and friends, they should have high level of awareness and knowledge regarding breast screening [24].

The overall results from this study suggest good knowledge about $\mathrm{BC}$ and the importance of its early diagnosis $(87.5 \%)$. The majority of participants understood that early detection is important in diagnoses and that $\mathrm{BC}$ is one of the three most common cancers affecting Jordanian women. However, only $12.5 \%$ chose all of the symptoms (nipple inversion, ulceration, focal nodularity, asymmetry with other breast, skin swelling) as important BC signs and symptoms, which raises concerns regarding early $\mathrm{BC}$ detection. 
Table 4. Association between personal information and practice performing breast examinations.

\begin{tabular}{|c|c|c|c|c|c|c|}
\hline \multirow[t]{2}{*}{ Variables } & \multicolumn{2}{|c|}{ BSE } & \multicolumn{2}{|c|}{ CBE } & \multicolumn{2}{|c|}{ Mammography } \\
\hline & Yes \% (n) & No $\%(n)$ & Yes \% (n) & No $\%(n)$ & Yes \% (n) & No $\%(n)$ \\
\hline \multicolumn{7}{|l|}{ Age } \\
\hline$<25$ & $30 \%(12)$ & $70 \%(28)$ & $18.1 \%(13)$ & $37.5 \%(27)$ & $7.4 \%(2)$ & $51.9 \%(14)$ \\
\hline $25-35$ & $9.7 \%(7)$ & $18.1 \%(13)$ & $5.6 \%(4)$ & $22.2 \%(16)$ & $0.0 \%(0)$ & $14.7 \%(4)$ \\
\hline $35-40$ & $2.8 \%(2)$ & $5.6 \%(4)$ & $4.2 \%(3)$ & $4.2 \%(3)$ & $3.7 \%(1)$ & $0.0 \%(0)$ \\
\hline More than 40 & $5.6 \%(4)$ & $2.8 \%(2)$ & $1.4 \%(1)$ & $6.9 \%(5)$ & $3.7 \%(1)$ & $18.5 \%(5)$ \\
\hline \multicolumn{7}{|l|}{ Gen der } \\
\hline Males & $11.1 \%(8)$ & $11.1 \%(8)$ & $8.3 \%(6)$ & $13.9 \%(10)$ & $3.7 \%(1)$ & $18.5 \%(5)$ \\
\hline \multirow[t]{2}{*}{ Females } & $23.6 \%(17)$ & $54 . \%(39)$ & $20.8 \%(15)$ & $56.9 \%(41)$ & $11.1 \%$ (3) & $66.7 \%(18)$ \\
\hline & \multicolumn{2}{|c|}{$\begin{array}{l}x^{2}=2.118 d f=1 \\
p \text {-value }=0.124\end{array}$} & \multicolumn{2}{|c|}{$\begin{array}{l}x 2=0.691 \mathrm{df}=1 \\
p \text {-value }=0.534\end{array}$} & \multicolumn{2}{|c|}{$\begin{array}{l}x^{2}=0.021 d f=1 \\
p \text {-value }=1\end{array}$} \\
\hline Radiographer & \multicolumn{2}{|c|}{$\begin{array}{l}x^{2}=1.961 d f=1 \\
p \text {-value }=0.158\end{array}$} & \multicolumn{2}{|c|}{$\begin{array}{l}x^{2}=1.891 d f=1 \\
p \text {-value }=0.220\end{array}$} & \multicolumn{2}{|c|}{$\begin{array}{l}x^{2}=0.587, d f=1 \\
p \text {-value }=0.605\end{array}$} \\
\hline \multicolumn{7}{|l|}{ Speciality } \\
\hline Breast imaging & $2.8 \%(2)$ & $4.2 \%(3)$ & $2.8 \%(2)$ & $4.2 \%(3)$ & $0.0 \%(0)$ & $3.7 \%(1)$ \\
\hline $\begin{array}{l}\text { Cardiovascular } \\
\text { radiology }\end{array}$ & $2.8 \%(2)$ & $5.6 \%(4)$ & $2.8 \%(2)$ & $5.6 \%(4)$ & $0.0 \%(0)$ & $3.7 \%(2)$ \\
\hline $\begin{array}{l}\text { Musculoskeletal } \\
\text { radiology }\end{array}$ & $6.9 \%(5)$ & $9.7 \%(7)$ & $5.6 \%(4)$ & $11.1 \%(8)$ & $0.0 \%(0)$ & $7.4 \%(2)$ \\
\hline \multirow[t]{2}{*}{ Other } & $22.2 \%(16)$ & $45.8 \%(33)$ & $18.1 \%(13)$ & $50.0 \%(36)$ & $100.0 \%(4)$ & $70.4 \%(19)$ \\
\hline & \multicolumn{2}{|c|}{$\begin{array}{l}x^{2}=0.414 d f=3 \\
p \text {-value }=0.937\end{array}$} & \multicolumn{2}{|c|}{$\begin{array}{l}x^{2}=0.600 \mathrm{df}=3 \\
p \text {-value }=0.896\end{array}$} & \multicolumn{2}{|c|}{$\begin{array}{l}x^{2}=0.817 d f=3 \\
p \text {-value }=0.847\end{array}$} \\
\hline Full time & $19.4 \%(14)$ & $43.1 \%(31)$ & $16.7 \%(12)$ & $45.8 \%(33)$ & $11.1 \%(3)$ & $48.1 \%(13)$ \\
\hline Part time & $15.3 \%(11)$ & $22.2 \%(16)$ & $12.5 \%(9)$ & $25.0 \%(18)$ & $3.7 \%(1)$ & $37.0 \%(10)$ \\
\hline & $\begin{array}{l}x^{2}=0.547 d \\
p \text {-value }=0\end{array}$ & & $\begin{array}{l}x^{2}=0.363 c \\
p \text {-value }=0\end{array}$ & & $\begin{array}{l}x^{2}=0.482 \\
p \text {-value }=c\end{array}$ & \\
\hline
\end{tabular}

Although female participants had good knowledge about breast examinations, low rates of practice in both BSE and CBE were seen. Overall, only $30.4 \%$ of the study participants performed BSE and $26.3 \%$ visited doctors to have $\mathrm{CBE}$. The low rates of $\mathrm{CBE}$ and $\mathrm{BSE}$ among radiology professionals in Jordan may be suggestive of inadequate emphasis on the importance of primary prevention in the radiographers and radiologists' curricula during education. In spite of the effort toward improving health education in the developing countries, it has been realized that in other medical domains, healthcare professionals, including nurses, are not adequately educated about cancer risk factors, risk assessment or cancer prevention [25]. This shortcoming in education may result in some difficulties in performing BSE. A case-control study was performed by Hassan et al. [26] to identify knowledge and practice BSE among nursing students. They found that only $52 \%$ of nursing students were able to perform BSE, which is similar to current study results. Therefore, educational intervention regarding BC and the significance of screening for BSE are vital steps in enhancing early detection [27]. The main purpose of the educational programs is to change radiology professionals behavior as they target their existing beliefs, which is an active way of developing screening practices [28]. 
Awareness campaigns about $\mathrm{BC}$ are considered effective educational methods as they increase women's motivation and improve the physicians' awareness and attitudes [29]. Previous studies stated that health care providers' education may help them to be more aware and sensitive to the customs and beliefs of Muslims [30]. BC screening could be promoted by using survivors from $\mathrm{BC}$ to educate women [31] and to change the typical view for cancer as a fatal disease to a chronic disease that can be defeated. Then women will be encouraged to undergo breast screening driven by the hope that they may survive a potential cancer [32]. The participation and interest of men in BC screening is also important as they may play a key role in saving Arab women's lives by encouraging and supporting breast examinations [31]. Therefore, men should play more of a role in encouraging and supporting breast examinations.

Several studies have noted that cancer prevention education is often absent from medical curricula [33]. Accordingly, producing and sharing evidence-based learning resources and including these in medical and allied curricula would be an important step in bridging the information gap. Based on the current data, it appears that there is a need for continuing professional education programs in radiology. Emphasis should be laid on CBE in undergraduate and postgraduate courses, especially for radiographers as they are mostly involved in patient care and education.

The largest proportion of study participants mentioned that time was the main obstacle that prevented them from doing these examinations. This finding agreed with other studies demonstrating that the responsibilities of working women forced them to postpone their own health affairs for the sake of their family members [34]. A potential solution would be for employers to help organize CBE in the place of employment, thus helping to overcome one of the barriers.

Although the current study showed that radiologists and radiographers aware of the benefits of mammogram screening, only one out of nine participants above 40 years underwent mammography. There may be several reasons for the low compliance. Dibble et al. [35] also reported factors such as mammography-induced pain and discomfort in addition to radiation exposure during a mammogram as reasons for not attending. Another explanation is that women may have the fear of being diagnosed with cancer. An addition consideration for medical personal is that they may be reserved about showing their breasts to their colleagues, which was a common finding. The strongest factor that could affect attendance at mammography is that study respondents did not believe that they would be susceptible to BC. Therefore, programs for radiologists and radiographers, especially for those who do not believe they may be diagnosed with BC, should be encouraged. Through such programs, awareness of screening as well as the importance of early diagnosis and prompt treatment should be emphasized.

Using self-reported data presents a number of limitations. First, mammography, CBE and BSE performance were self-reported, whereas certainly $\mathrm{CBE}$ and mammography data can be extracted with more validity via medical record review. Any voluntary survey is potentially subject to some selection bias [36]. Moreover, most of the study participants were younger than 40 years, which could affect the mammography screening results. Future work will focus on assessing the knowledge, attitude and practice of radiology professionals. We can set a standard and compare the knowledge and attitude in nonprofessional groups.

Our findings are in agreement with the findings from a previous study done among general practitioners in Australia [37]; their lack of knowledge of some aspects of $\mathrm{BC}$ is problematic. Not having the correct information may lead them to provide incorrect information to the patients about BC. In the UK, a study of general practitioner's knowledge about $\mathrm{BC}$ risk factors showed that more than half of the participants were able to correctly identify BC symptoms as compared to $12.5 \%$ in our study [38]. Therefore, we recommend more continuing professional education for radiographers and radiologists on BSE, CBE and screening.

Further work is needed to encourage radiologists and radiographers to undertake breast examination assessment courses in order to learn BSE and encourage them to visit doctors to perform both CBE and mammography.

\section{Conclusion}

This is the first study in Jordan that assesses the knowledge, attitudes and practice of radiologists and radiographers about breast examinations. The results demonstrate that radiologists and radiographers are aware of the benefits of $\mathrm{BC}$ screening and its ability to facilitate early diagnosis of BC. They advise relatives to undertake screening. However, there was a low incidence of participation in BSE, CBE and mammography. Time, knowledge and social factors were barriers. Information on how to perform BSE, and time to undergo CBE should be considered as priority interventions in this workforce. 


\section{Summary points}

- Radiology professionals carry responsibility of improving the society's health by being a direct source of accurate knowledge of breast examinations.

- Radiology professionals can have a considerable influence on their patients and friends therefore should have high level of awareness and knowledge regarding breast screening.

- Radiology professionals are aware of the benefits of breast cancer screening and its ability to facilitate early diagnosis of breast cancer.

- Only $30.4 \%$ of the study participants performed breast self-examinations (BSE), and $26.3 \%$ visited doctors to have clinical breast examination (CBE).

- Time, knowledge and social factors are major barriers facing radiology professionals in breast examinations.

- Information on how to perform BSE, and time to undergo CBE should be considered as priority interventions in this workforce.

- This study recommends more continued professional education for radiology professionals on BSE, CBE and mammographic screening.

Financial \& competing interests disclosure

The authors have no relevant affiliations or financial involvement with any organization or entity with a financial interest in or financial conflict with the subject matter or materials discussed in the manuscript. This includes employment, consultancies, honoraria, stock ownership or options, expert testimony, grants or patents received or pending, or royalties.

No writing assistance was utilized in the production of this manuscript.

\section{Ethical disclosure}

The authors state that they have obtained appropriate institutional review board approval or have followed the principles outlined in the Declaration of Helsinki for all human or animal experimental investigations. In addition, for investigations involving human subjects, informed consent has been obtained from the participants involved under the ethics no. (261/2018).

\section{Author contributions}

Guarantor of integrity of entire study, M Rawashdeh; study concepts/study design or data acquisition or data analysis/interpretation, all authors; data collection, M Rawashdeh; manuscript drafting or manuscript revision for important intellectual content, all authors; approval of final version of submitted manuscript, all authors; literature research, M Rawashdeh; study design, all authors; statistical analysis, M Rawashdeh and manuscript editing, all authors.

\section{Open access}

This work is licensed under the Attribution-NonCommercial-NoDerivatives 4.0 Unported License. To view a copy of this license, visit http://creativecommons.org/licenses/by-nc-nd/4.0/

\section{References}

Papers of special note have been highlighted as: • of interest; $\bullet \bullet$ of considerable interest

1. Data WOW. World Cancer Research Fund International. (2018). www.wcrf.org/int/cancer-facts-figures/worldwide-data

2. Statistics KJL. King Hussein Cancer Foundation. (2018). www.khcc.jo/section/local-statistics

3. (Aihw) AIOHaW. Cancer Australia\& Australasian Association of Cancer Registries 2008. Cancer survival and prevalence in Australia: cancers diagnosed from 1982 to 2004. Cancer Series no. 42. Cat. no. CAN 38. Canberra: AIHW (2004). www.aihw.gov.au/reports/cancer/cancer-survival-and-prevalence-in-australia-cance/contents/table-of-contents

4. Statistics OFN. Cancer Statistics registrations: Registrations of cancer diagnosed in 2005, England. Series MB1 no.36. 2008 National Statistics: London (2008). www.ons.gov.uk/peoplepopulationandcommunity/healthandsocialcare/conditionsanddiseases/bulletins/cancer registrationstatisticsengland/2014-06-19

5. Harper S, Lynch J, Meersman SC, Breen N, Davis WW, Reichman MC. Trends in area-socioeconomic and race-ethnic disparities in breast cancer incidence, stage at diagnosis, screening, mortality, and survival among women ages 50 years and over (1987-2005). Cancer Epidemiol. Biomarkers Prev. 18(1), 121-131 (2009).

6. P CMD. Breast Cancer: Practice Essentials, Background, Anatomy. (2018). https://emedicine.medscape.com/article/1947145-overview

7. Kerlikowske K, Grady D, Rubin SM, Sandrock C, Ernster VL. Efficacy of screening mammography: a meta-analysis. JAMA 273(2), 149-154 (1995).

8. Moskowitz M. Mammography to screen asymptomatic women for breast cancer. Am. J. Roentgenol. 143(3), 457-459 (1984). 
9. Minn H, Soini I. [18F] Fluorodeoxyglucose scintigraphy in diagnosis and follow up of treatment in advanced breast cancer. Eur. J. Nucl. Med. 15(2), 61-66 (1989).

10. Cancer. Org Breast Cancer Survival Rates \& Statistics. (2018). www.cancer.org/cancer/breast-cancer/understanding-a-breast-cancer-diagnosis/breast-cancer-survival-rates.html

11. Heywang-Köbrunner SH, Hacker A, Sedlacek S. Advantages and disadvantages of mammography screening. Breast Care 6(3), 199-207 (2011).

12. Kakushadze Z, Raghubanshi R, Yu W. Estimating cost savings from early cancer diagnosis. Data 2(3), 30 (2017).

13. Nimir AR, Al-Dubai SA, Alshagga MA, Saliem AM. Knowledge and practice of breast self-examination among students in a private higher learning institution in malaysia. Malaysian J. Public Health Med. 14(3), 47-53 (2014).

14. Akpınar YY, Baykan Z, Naçar M, Gün I, Çetinkaya F. Knowledge, attitude about breast cancer and practice of breast cancer screening among female health care professionals: a study from Turkey. Asian Pacific J. Cancer Prev. 12(11), 3063-3068 (2011).

15. Provencher L, Hogue J, Desbiens C et al. Is clinical breast examination important for breast cancer detection? Curr. Oncol. 23(4), e332 (2016).

16. King Hussain Cancer Center. Breast Cancer and Early Screening 1st Ed., Amman, 3-9 (2018).

17. (N.D.) PL. Price List. (n.d.). (2018). www.khcc.jo/section/price-list

18. Kumar S, Imam AM, Manzoor NF, Masood N. Knowledge, attitude and preventive practices for breast cancer among health care professionals at Aga Khan Hospital Karachi. J. Pak. Med. Assoc. 59(7), 474 (2009).

-• This study is very relevant to our study as it deals with healthcare professionals as a sample.

19. Lee J, Gordon PB, Whitman GJ. Do unto others as you would have them do unto you: breast imagers' perspectives regarding screening mammography for others and for themselves - do they practice what they preach? Am. J. Roentgenol. 204(6), 1336-1344 (2015).

-. Includes breast imagers' perspectives regarding screening mammography for others and for themselves.

20. Doshi D, Reddy BS, Kulkarni S, Karunakar P. Breast self-examination: knowledge, attitude, and practice among female dental students in Hyderabad city, India. Indian J. Palliat. Care 18(1), 68 (2012).

21. Odusanya OOT, Olumuyiwa. Breast cancer knowledge, attitudes and practice among nurses in Lagos, Nigeria. Acta Oncol. 40(7), 844-848 (2001).

22. Jarvandi S, Montazeri A, Harirchi I, Kazemnejad A. Beliefs and behaviours of Iranian teachers toward early detection of breast cancer and breast self-examination. Public Health 116(4), 245-249 (2002).

23. Field LJ, Snaith BA. Developing radiographer roles in the context of advanced and consultant practice. J. Med. Radiat. Sci. 60(1), 11-15 (2013).

24. Donnelly TT, Al Khater A-H, Al-Bader SB et al. Arab women's breast cancer screening practices: a literature. Asian Pac. J. Cancer Prev. 14(8), 4519-4528 (2013).

- Significant as it deals with the Arabian culture and its effects on such a subject.

25. Mahon SM. Cancer risk assessment: conceptual considerations for clinical practice. Presented at: Oncology Nursing Forum. PA, USA (1998).

26. Abu Salem O, Hassan MA. Breast self-examination among female nurses. Qatar Med. J. 2007(1), 7 (2007).

27. Montazeri A, Vahdaninia M, Harirchi I et al. Breast cancer in Iran: need for greater women awareness of warning signs and effective screening methods. Asia Pac. Fam. Med. 7(1), 6 (2008).

28. Petro-Nustus W, Mikhail BI. Factors associated with breast self-examination among Jordanian women. Public Health Nurs. 19(4), 263-271 (2002).

- $\quad$ Provides perspective on the status of breast self-examination among Jordanian women.

29. El Saghir NS. Responding to the challenges of breast cancer in Egypt and other Arab countries. J. Egypt Natl Canc. Inst. 20(4), 309-312 (2008).

30. Banning M, Hafeez H. A two-center study of Muslim women's views of breast cancer and breast health practices in Pakistan and the UK. J. Cancer Educ. 25(3), 349-353 (2010).

31. Remennick $\mathrm{L}$. The challenge of early breast cancer detection among immigrant and minority women in multicultural societies. Breast J. 12, S103-S110 (2006).

- Contributes to knowledge on the barriers to breast cancer care in developing countries where they can be linked to the results of our study.

32. Baron-Epel O, Klin A. Cancer as perceived by a middle-aged Jewish urban population in Israel. Presented at: Oncology Nursing Forum. PA, USA (2009).

33. Geller AC, Prout M, Sun T, Lew RA, Culbert AL, Koh HK. Medical students' knowledge, attitudes, skills, and practices of cancer prevention and detection. J. Cancer Educ. 14(2), 72-77 (1999). 
34. Sharma K, Costas A, Shulman LN, Meara JG. A systematic review of barriers to breast cancer care in developing countries resulting in delayed patient presentation. J. Oncol. 2012, 2012 (2012).

- Contributes to knowledge on the barriers to breast cancer care in developing countries where they can be linked to the results of our study.

35. Dibble SL, Vanoni JM, Miaskowski C. Women's attitudes toward breast cancer screening procedures: differences by ethnicity. Women's Health Issues 7(1), 47-54 (1997).

- Significant as it reveals the psychological aspects of breast cancer screening procedures on women.

36. Yerramilli P, Dugee O, Enkhtuya P, Knaul FM, Demaio AR. Exploring knowledge, attitudes, and practices related to breast and cervical cancers in Mongolia: a National population-based survey. Oncologist 20(11), 1266-1273 (2015).

37. Cockburn J, Irwig L, Turnbull D, Simpson J, Mock P, Tattersall M. Encouraging attendance at screening mammography: knowledge, attitudes and intentions of general practitioners. Med. J. Aust. 151(7), 391-396 (1989).

-• The results of this study are significant as it deals with the general practitioner's role in encouraging screening mammography.

38. Kushi LH, Doyle C, Mccullough M et al. American Cancer Society Guidelines on nutrition and physical activity for cancer prevention: reducing the risk of cancer with healthy food choices and physical activity. CA Cancer J. Clin. 62(1), 30-67 (2012). 
